\title{
Proteins and single nucleotide polymorphisms involved in apoptosis, growth control, and DNA repair predict cisplatin sensitivity in head and neck cancer cell lines
}

\author{
LOVISA FARNEBO ${ }^{1}$, ADAM JEDLINSKI ${ }^{1}$, ANNA ANSELL ${ }^{1}$, LINDA VAINIKKA ${ }^{1}$, LENA K. THUNELL ${ }^{2}$, \\ REIDAR GRÉNMAN $^{3}$, ANN-CHARLOTTE JOHANSSON ${ }^{1,4}$ and KARIN ROBERG ${ }^{1}$ \\ ${ }^{1}$ Division of Otorhinolaryngology, Linköping University Hospital, Linköping; ${ }^{2}$ Division of Cell Biology, Department of \\ Clinical and Experimental Medicine, Linköping University, Sweden; ${ }^{3}$ Department of Otorhinolaryngology, \\ Head and Neck Surgery and Medical Biochemistry, University of Turku, Finland; \\ ${ }^{4}$ Cancer Center Karolinska, Karolinska Institute, Stockholm, Sweden
}

Received May 18, 2009; Accepted June 19, 2009

DOI: 10.3892/ijmm_00000264

\begin{abstract}
The present study was undertaken to evaluate the possibility of using a panel of proteins and single nucleotide polymorphisms (SNPs) involved in apoptosis, growth control, and DNA repair as predictive markers for cisplatin sensitivity. For this purpose the intrinsic cisplatin sensitivity (ICS) was determined in 39 cell lines derived from squamous cell carcinomas of the head and neck using a colony-forming assay. In these cell lines and in normal oral keratinocytes (NOK), the expression of epidermal growth factor receptor (EGFR), Hsp70, Bax, Bcl-2, Bcl-XL, survivin, and COX-2 was determined. Moreover, the p53, MDM2, FGFR4, XPC, XPD, $\mathrm{XRCC} 1$, and $\mathrm{XRCC} 3$ genes were analyzed for the presence of specific single nucleotide polymorphisms (SNPs). Pearson's correlation test showed that EGFR was the only protein that was significantly correlated to the ICS $(r=0.388, p=0.015)$. The combination of EGFR, Hsp70, Bax, and Bcl-2 gave the strongest correlation $(\mathrm{r}=0.566, \mathrm{p} \leq 0.001)$, whereas Bax alone had the second highest influence on the ICS. Furthermore, all four SNPs within genes involved in DNA repair, i.e. XPC, $\mathrm{XPD}, \mathrm{XRCC} 1$, and XRCC3, tended to influence the ICS. In order to find the combination of factors, on both protein and gene levels, with the highest correlation to ICS, a multivariate statistical calculation was performed. Our results indicate that SNPs in DNA repair genes (XRCC $3^{241}$ and $\mathrm{XPD}^{751}$ ) influence the ICS and together with the expression of EGFR, Hsp70, $\mathrm{Bax}$, and $\mathrm{Bcl}-2$, they could predict the cisplatin sensitivity of head and neck cancer cell lines $(r=0.614, p \leq 0.001)$.
\end{abstract}

Correspondence to: Dr Karin Roberg, Division of Otorhinolaryngology, Linköping University Hospital, 58185 Linköping, Sweden

E-mail: karin.roberg@liu.se

Key words: epidermal growth factor receptor, Bax, Bcl-2, heat shock protein 70, DNA repair genes

\section{Introduction}

Cancer of the head and neck poses a major health problem in the world, and is the sixth most prevalent of all cancer types. The majority of all head and neck cancers are squamous cell carcinomas originating from epithelial tissues (1). A combination of radiotherapy and surgery or definitive chemoirradiation are the primary modes of treatment for locally advanced head and neck squamous cell carcinoma (HNSCC). Treatment resistance and local recurrence are significant problems following therapy, thus there is a paramount need for predictive markers (2). Cisplatin is the backbone of chemotherapy regimens used to treat HNSCC, and its main cytotoxic activity is based on the formation of DNA adducts. These adducts block replication, inhibit transcription, and are repaired by different DNA repair pathways, including nucleotide excision repair (NER), base excision repair (BER), and double strand break repair (DSBR) (3).

Among the molecular mechanisms involved in carcinogenesis, defects in the regulation of growth control and apoptosis may be important for the progression, pathogenesis, and treatment response of tumors. The p53 tumor suppressor gene is the most frequently mutated gene in human cancers, and the function of the $\mathrm{p} 53$ protein can be affected by mutations or altered expression of proteins involved in the p53 pathway. It is assumed that $\mathrm{p} 53$, together with anti-apoptotic proteins like Bcl-XL and Bcl-2 and pro-apoptotic proteins such as Bax, Bad, Bak (4,5), and PUMA (6), regulates the sensitivity of the tumors to chemotherapy.

The epidermal growth factor receptor (EGFR) and its ligands are fundamentally important for cell division, migration, adhesion, invasion, and angiogenesis. EGFR overexpression has been reported in $>80 \%$ of HNSCC tumors and is found to be associated with a more aggressive phenotype, poor prognosis, and resistance to chemotherapeutic agents (7). Anti-EGFR antibodies and tyrosine kinase inhibitors which block EGFR signaling have recently been developed, and the monoclonal antibody cetuximab $\left(\right.$ Erbitux $\left.^{\circledR}\right)$ was approved for the treatment of advanced HNSCC (8). 
Cyclooxygenase-2 (COX-2) is an inducible enzyme whose expression can be upregulated by endogenous factors such as inflammatory cytokines, oncogenes, certain growth factors, and hypoxia (9). COX-2 is constitutively expressed in many different cancers, including those of the head and neck, and has been shown to be involved in carcinogenesis, tumor growth, metastatic spread, and resistance to cytotoxic therapy $(10,11)$.

It has been validated that survivin, a member of the 'inhibitors of apoptosis proteins' (IAPs) protein family, plays a vital role in tumor cell survival. Survivin, which is largely undetectable in normal mucosa, is highly expressed in most HNSCCs, and its expression is associated with a more aggressive and invasive phenotype, as well as resistance to therapy-induced apoptosis (12).

Heat shock proteins (Hsps) are chaperones that assist proteins in their folding and stability. Due to their anti-apoptotic properties, intracellular Hsps allow cells to survive under lethal conditions. In cancer cells, an abnormally high expression of Hsp70 has been associated with oncogenesis and resistance to chemotherapy (13), thus, Hsp70 was included in this study.

Seven SNPs, all of which were previously reported to have an impact on treatment response in cancer, were included in this study. As the p53 pathway is known to be involved in cancer treatment response and is capable of either arresting the cell cycle or inducing apoptosis in a dose-dependent manner (14), two SNPs within genes from this pathway were chosen (p5372 and MDM2 ${ }^{309}$ ). It has been hypothesized that in tumor cells exposed to cisplatin, an impaired function of the different DNA repair systems would lead to more extensive DNA damage and, thus, cell death. In this study, the impact of four SNPs in the NER, BER, and DSBR systems on cisplatin resistance was investigated $\left(\mathrm{XPC}^{499}, \mathrm{XPD}^{751}, \mathrm{XRCC}^{399}\right.$, and $\mathrm{XRCC}^{241}$ ). Fibroblast growth factor receptors (FGFRs) consist of four closely related genes (FGFR1-4) with a similar protein structure, all belonging to the receptor tyrosine kinase family. FGFRs are believed to be involved in many human cancers, such as cervical, bladder, and breast cancers (15). In a previous study, we presented evidence that an SNP in position 388 of the transmembrane domain of FGFR4 influenced the cisplatin sensitivity of $35 \mathrm{HNSCC}$ cell lines (16). The potential role of the FGFR $4{ }^{388} \mathrm{SNP}$ as a predictive marker was further evaluated in the present study.

Taken together, many proteins have been shown to influence cisplatin sensitivity in vitro, but it is difficult to obtain a significant correlation between expression of a single marker and treatment sensitivity. Therefore, the present study was undertaken to evaluate the possibility of using combinations of multiple factors to predict the intrinsic cisplatin sensitivity (ICS) of HNSCC cell lines. For this purpose, seven proteins (EGFR, Hsp70, Bax, Bcl-2, Bcl-XL, survivin, and COX-2) and seven SNPs (p53 ${ }^{72}, \mathrm{MDM}^{309}, \mathrm{FGFR}{ }^{388}, \mathrm{XPC}^{499}, \mathrm{XPD}^{751}$, $\mathrm{XRCC} 1{ }^{399}$, and $\mathrm{XRCC} 3^{241}$ ), all of which have been previously reported to influence treatment sensitivity, were selected. We also wanted to evaluate whether a correlation exists between the ICS and the intrinsic radiosensitivity (IR) of these cell lines.

We recently established a new method in which both changes in protein expression and genetic alterations are evaluated and correlated to the treatment response. The method was named 'the Number of Negative Points system' (NNP), as it combines different factors that are positive for tumor growth, although negative for the host of the tumor, i.e. the patient (17). Here, the NNP system was used for analysis of the combined effect of selected factors on cisplatin sensitivity in 39 HNSCC cell lines.

\section{Materials and methods}

Cells and culture conditions. The 39 HNSCC cell lines were provided by the University of Turku, Department of Otorhinolaryngology, Head and Neck Surgery, Finland (Table I). The cell lines were cultured in Dulbecco's Modified Eagle's Medium, supplemented with $2 \mathrm{mM}$ glutamine, $1 \%$ non-essential amino acids, $100 \mathrm{IU} / \mathrm{ml}$ penicillin-G, $50 \mu \mathrm{g} / \mathrm{ml}$ streptomycin, and $10 \%$ fetal bovine serum (all from Gibco, Paisley, UK). The cells were incubated in humidified air with $5 \% \mathrm{CO}_{2}$ at $37^{\circ} \mathrm{C}$, and subcultured once a week using $0.25 \%$ trypsin $+0.02 \%$ EDTA.

Normal human oral keratinocytes (NOK) were cultured as previously described (18). Biopsies were harvested during benign surgery in the oral cavity, mostly tonsillectomies, and contained non-keratinized squamous cell epithelium (approved by the Linköping University Ethics Committee). Primary keratinocyte cultures were derived from trypsin-digested tissue, and cultured in growth medium (Keratinocyte-SFM; Gibco) supplemented with antibiotics (penicillin $100 \mu / \mathrm{ml}$, streptomycin $100 \mu \mathrm{g} / \mathrm{ml}$ ) in culture flasks pre-coated with fibronectin and collagen. Medium was replaced every third day, and cultures were subcultured at about $75 \%$ confluence using $0.25 \%$ trypsin $+0.02 \%$ EDTA. Cultures from passages two and three were used for the analyses.

Assessment of intrinsic cisplatin sensitivity (ICS). The effect of cisplatin was determined by a clonogenic assay. Tumor cells were seeded into six-well plates at densities of 200-400 cells $/ \mathrm{cm}^{2}$ depending on the plating efficiency of each cell line. After $24 \mathrm{~h}$, cells were exposed to cisplatin $(1 \mu \mathrm{g} / \mathrm{ml})$ for $1 \mathrm{~h}$ and incubated for another 9 days before fixation in $4 \%$ formalin, staining with $2 \%$ Giemsa (Merck, Whitehouse Station, NJ, USA), and counting of colonies containing $\geq 32$ cells. The ICS values for different cell lines varied between 0 and 1 where an ICS of $1=100 \%$ survival (as compared to untreated controls). All cell lines were exposed to cisplatin at least twice in triplicate using two different batches of fetal calf serum (Gibco), and the mean value was used for statistical analyses. The highest variation in ICS value between experiments with different serum batches was \pm 0.1 (cell lines UT-SCC-10 and -19A). The relationship between ICS and the above mentioned factors was statistically evaluated both for single factors and combinations of factors. The importance of EGFR for ICS was further investigated in 4 of the HNSCC cell lines, each of which had different levels of EGFR expression, using an anti-EGFR monoclonal antibody (cetuximab, Erbitux; $30 \mathrm{ng} / \mathrm{ml}$, Merck KGaA, Darmstadt, Germany). The cytostatic/cytotoxic effect of cetuximab alone or in combination with cisplatin was determined by crystal violet staining following fixation in $4 \%$ paraformaldehyde (20 min). Surviving (adherent) cells were stained with $0.04 \%$ crystal violet in $1 \%$ ethanol for $20 \mathrm{~min}$ at room temperature, and the plates were washed extensively under running tap water and air dried. Optical density values were recorded in a Victor 
plate reader (EG \& G Wallac, Upplands Väsby, Sweden) at $550 \mathrm{~nm}$ after solubilization of samples in $1 \%$ SDS.

Assessment of intrinsic radiosensitivity (IR). The tumor cells were grown to mid-logarithmic phase and fed with fresh medium $24 \mathrm{~h}$ before the experiments. The 96-well plate clonogenic assay was performed as previously described $(19,20)$. In brief, the cells were harvested with trypsin/ EDTA, counted, and diluted to form a stock solution. The number of cells plated per well was adjusted according to the plating efficiency of each cell line. After plating, cells were allowed to attach for $24 \mathrm{~h}$ before irradiation. Cells were irradiated with $4 \mathrm{MeV}$ photons generated by a linear accelerator (Clinac 4/100, Varian, Palo Alto, CA, USA), delivering a dose-rate of $2.0 \mathrm{~Gy} / \mathrm{min}$. After incubating the plates for 4 weeks, the number of positive wells was counted using a phase-contrast microscope. Wells with colonies consisting of at least 32 cells were considered positive.

Survival data as a function of the radiation dose were fitted by a linear quadratic equation, and the area under curve (AUC) was obtained by numerical integration (21). For each cell line, a minimum of three experiments were performed.

ELISA analysis. Cells were washed in phosphate-buffered saline (PBS), and lysed in a lysis buffer ( $\mathrm{pH}$ 7.2) containing $1 \mathrm{mM}$ EDTA, $0.5 \%$ Triton X-100, $10 \mu \mathrm{g} / \mathrm{ml}$ leupeptin, $10 \mu \mathrm{g} /$ $\mathrm{ml}$ pepstatin, $100 \mu \mathrm{M}$ PMSF, and $3 \mu \mathrm{g} / \mathrm{ml}$ aprotinin in PBS (all from Sigma, St Louis, MO, USA). The protein concentration was determined (22), and the lysates were stored at $-20^{\circ} \mathrm{C}$ until analysis. The amount of EGFR, Bax, Bcl-2, BclXL, Hsp-70, and survivin was determined using a Duo Set IC ELISA kit (R\&D Systems, Minneapolis, MN, USA), and the amount of COX-2 was determined using a COX-2 ELISA kit (Calbiochem, Merck KGaA). All assays were conducted according to the suppliers' recommendations. The optical densities of all samples were determined using a microplate reader (Versa max, Molecular Devices Corp, Sunnyvale, CA, USA). All analyses were performed three times and the mean values were used for further calculations.

DNA isolation. Isolation of DNA from cell lines was performed with a Maxwell 16 DNA Purification Kit (Promega, Madison, WI, USA).

Polymerase Chain Reaction (PCR) and Restriction Fragment Length Polymorphism (RFLP) analysis. The p53, FGFR4, XPC, XPD, XRCC1, and XRCC3 genes were amplified by PCR in separate reactions. The sequences of the primers and the conditions for the different genes are available upon request. Each PCR reaction was carried out in a $20 \mu 1$ reaction volume with a final concentration of $20 \mathrm{mM}\left(\mathrm{NH}_{4}\right)_{2} \mathrm{SO}_{4}, 75 \mathrm{mM}$ Tris- $\mathrm{HCl}$ (pH 9.0), 0.01\% Tween-20, $200 \mu \mathrm{M}$ of each dNTP, $2.0 \mathrm{mM} \mathrm{MgCl}_{2}, 0.1-1.0 \mu \mathrm{M}$ of each primer (Invitrogen, Paisley, UK), 0.5 U Taq DNA polymerase (Thermowhite, Saveen Werner AB, Limhamn, Sweden), and 50 ng DNA. In PCR reactions for $\mathrm{p} 53,5 \%$ DMSO was also included. The amplification was performed at annealing temperatures from 55 to $62^{\circ} \mathrm{C}$, depending on the gene, for 35 cycles. Samples were loaded on a $1.5 \%$ agarose gel (Invitrogen) and stained with ethidium bromide for detection of PCR products on a
UV table. The p53 ${ }^{72}$, FGFR4 ${ }^{388}, \mathrm{XPC}^{499}, \mathrm{XPD}^{751}, \mathrm{XRCC}^{399}$, and XRCC $3{ }^{241}$ SNPs were detected by using restriction enzymes according to the manufacturer's instructions. Restriction fragments were resolved on 3\% Nusieve: $1 \%$ agarose gels (Invitrogen), and stained with ethidium bromide for detection.

Polymerase chain reaction (PCR) and Pyrosequencing of $M D M 2^{309}$. A fragment in the MDM2 gene was amplified using a biotinylated reverse primer. Sequences of the primers are available upon request. Each PCR mixture had a total volume of $30 \mu \mathrm{l}$, and consisted of $1.0 \mu \mathrm{M}$ of each primer (Invitrogen), $200 \mu \mathrm{M}$ of each dNTP, $2.0 \mathrm{mM} \mathrm{MgCl} 2,20 \mathrm{mM}$ $\left(\mathrm{NH}_{4}\right)_{2} \mathrm{SO}_{4}, 75 \mathrm{mM}$ Tris ( $\mathrm{pH} 9.0$ ), 0.01\% Tween-20, 0.5 U Taq DNA polymerase (Thermowhite), and $50 \mathrm{ng}$ DNA. For the real-time sequencing of the PCR products and SNP analysis, a Pyrosequencing PSQ96MA system (Pyrosequencing AB, Uppsala, Sweden) was used. Single-stranded DNA was isolated from the PCR reaction using the Pyrosquencing Vacuum Prep Workstation (Pyrosequencing AB) and transferred into a 96-well plate. The sequencing primer was annealed to the single-stranded DNA by heating the sample to $80^{\circ} \mathrm{C}$ for $2 \mathrm{~min}$, and allowing it to cool to room temperature. The plate was then transferred to the PSQ96MA where the real-time sequencing took place.

Number of negative points. The NNP system was previously introduced by our group, and enables the simultaneous evaluation of factors on both the protein and gene level (17). For each cell line, the expression levels (the mean value from three ELISA analyses) of the seven proteins were converted into points. Each protein was allocated up to 3 points depending on its relative expression as compared to NOK, according to the following criteria: 0 points, no change in expression (01.50 -fold); 1 point, small changes in expression (1.51-4.50-fold); 2 points, intermediate changes in expression (4.51-7.50-fold); 3 points, large changes in expression ( $\geq 7.51$-fold), as compared to NOK. The points are either positive or negative depending on the benefit of that protein for the patient. For example, an overexpression of the pro-apoptotic protein Bax, as well as an underexpression of the anti-apoptotic protein $\mathrm{Bcl}-2$, are considered to be beneficial for the patient and were therefore given negative points in the NNP system. Furthermore, each SNP generated 1 point in the NNP system, either positive or negative, depending on whether the median ICS of cell lines with the SNP was equal or higher (positive) or lower (negative) than the cell lines expressing the wild-type gene.

Statistics. The Mann-Whitney U test was used for analysis of the significance of the SNPs for cisplatin sensitivity. The correlation between the expression of each protein and the ICS, as well as the influence of combinations of NNP values from two or more proteins on the ICS, were analyzed using Pearson's correlation test (2-tailed; SPSS 15.0.1 for Windows, SPSS Inc. Chicago, IL, USA).

A multivariate statistical calculation was carried out to identify the combination of factors having the strongest correlation to ICS. The seven proteins and the seven SNPs were classified using the NNP system. These factors were combined in all possible variants, using a multivariate computer calculation. This calculation gave 16,383 different 
Table I. Tumor characteristics including intrinsic cisplatin sensitivity (ICS) and intrinsic radiosensitivity (IR).

\begin{tabular}{|c|c|c|c|c|}
\hline Cell line & $\mathrm{ICS}^{\mathrm{a}}$ & $\mathrm{IR}^{\mathrm{b}}$ & Primary tumor location & $\mathrm{TNM}^{\mathrm{c}}$ \\
\hline UT-SCC-1A & 0.58 & 1.7 & Gingiva & $\mathrm{T}_{2} \mathrm{~N}_{1} \mathrm{M}_{0}$ \\
\hline UT-SCC-2 & 1.00 & 1.8 & Floor of mouth & $\mathrm{T}_{4} \mathrm{~N}_{1} \mathrm{M}_{0}$ \\
\hline UT-SCC-5 & 0.50 & 2.3 & Supraglottic larynx & $\mathrm{T}_{1} \mathrm{~N}_{1} \mathrm{M}_{0}$ \\
\hline UT-SCC-7 & 0.32 & 2.0 & Temporal skin & $\mathrm{T}_{1} \mathrm{~N}_{0} \mathrm{M}_{0}$ \\
\hline UT-SCC-8 & 0.52 & 1.9 & Supraglottic larynx & $\mathrm{T}_{2} \mathrm{~N}_{0} \mathrm{M}_{0}$ \\
\hline UT-SCC-9 & 0.88 & 1.4 & Glottic larynx & $\mathrm{T}_{2} \mathrm{~N}_{1} \mathrm{M}_{0}$ \\
\hline UT-SCC-10 & 0.64 & 1.9 & Tongue & $\mathrm{T}_{1} \mathrm{~N}_{0} \mathrm{M}_{0}$ \\
\hline UT-SCC-11 & 0.28 & 2.0 & Glottic larynx & $\mathrm{T}_{1} \mathrm{~N}_{0} \mathrm{M}_{0}$ \\
\hline UT-SCC-12A & 0.00 & 2.1 & Nasal skin & $\mathrm{T}_{2} \mathrm{~N}_{0} \mathrm{M}_{0}$ \\
\hline UT-SCC-14 & 0.43 & 1.7 & Tongue & $\mathrm{T}_{3} \mathrm{~N}_{1} \mathrm{M}_{0}$ \\
\hline UT-SCC-15 & 0.43 & 2.1 & Tongue & $\mathrm{T}_{1} \mathrm{~N}_{0} \mathrm{M}_{0}$ \\
\hline UT-SCC-16A & 0.66 & 1.8 & Tongue & $\mathrm{T}_{3} \mathrm{~N}_{0} \mathrm{M}_{0}$ \\
\hline UT-SCC-17 & 0.09 & 1.8 & Supraglottic larynx & $\mathrm{T}_{2} \mathrm{~N}_{0} \mathrm{M}_{0}$ \\
\hline UT-SCC-18 & 0.34 & 1.8 & Gingiva & $\mathrm{T}_{3} \mathrm{~N}_{1} \mathrm{M}_{0}$ \\
\hline UT-SCC-19A & 0.35 & 1.7 & Glottic larynx & $\mathrm{T}_{4} \mathrm{~N}_{0} \mathrm{M}_{0}$ \\
\hline UT-SCC-20A & 0.47 & 2.1 & Floor of mouth & $\mathrm{T}_{1} \mathrm{~N}_{0} \mathrm{M}_{0}$ \\
\hline UT-SCC-21 & 0.63 & 1.8 & Tongue & $\mathrm{T}_{3} \mathrm{~N}_{0} \mathrm{M}_{0}$ \\
\hline UT-SCC-22 & 0.49 & 1.8 & Glottic larynx & $\mathrm{T}_{1} \mathrm{~N}_{0} \mathrm{M}_{0}$ \\
\hline UT-SCC-23 & 0.06 & 1.6 & Glottic larynx & $\mathrm{T}_{3} \mathrm{~N}_{0} \mathrm{M}_{0}$ \\
\hline UT-SCC-24A & 1.00 & 2.6 & Tongue & $\mathrm{T}_{2} \mathrm{~N}_{0} \mathrm{M}_{0}$ \\
\hline UT-SCC-24B & 0.56 & 2.3 & Tongue & $\mathrm{T}_{2} \mathrm{~N}_{0} \mathrm{M}_{0}$ \\
\hline UT-SCC-29 & 0.79 & 1.8 & Glottic larynx & $\mathrm{T}_{2} \mathrm{~N}_{0} \mathrm{M}_{0}$ \\
\hline UT-SCC-30 & 0.69 & 2.0 & Tongue & $\mathrm{T}_{3} \mathrm{~N}_{1} \mathrm{M}_{0}$ \\
\hline UT-SCC-32 & 0.43 & 1.7 & Tongue & $\mathrm{T}_{3} \mathrm{~N}_{0} \mathrm{M}_{0}$ \\
\hline UT-SCC-33 & 0.70 & 2.3 & Gingiva & $\mathrm{T}_{2} \mathrm{~N}_{0} \mathrm{M}_{0}$ \\
\hline UT-SCC-34 & 0.74 & 2.1 & Supraglottic larynx & $\mathrm{T}_{4} \mathrm{~N}_{0} \mathrm{M}_{0}$ \\
\hline UT-SCC-36 & 0.69 & 2.2 & Floor of mouth & $\mathrm{T}_{4} \mathrm{~N}_{1} \mathrm{M}_{0}$ \\
\hline UT-SCC-38 & 0.53 & 2.3 & Glottic larynx & $\mathrm{T}_{2} \mathrm{~N}_{0} \mathrm{M}_{0}$ \\
\hline UT-SCC-40 & 0.55 & 2.3 & Tongue & $\mathrm{T}_{3} \mathrm{~N}_{0} \mathrm{M}_{0}$ \\
\hline UT-SCC-42A & 0.77 & 2.1 & Supraglottic larynx & $\mathrm{T}_{4} \mathrm{~N}_{3} \mathrm{M}_{0}$ \\
\hline UT-SCC-43A & 0.48 & 1.8 & Gingiva & $\mathrm{T}_{4} \mathrm{~N}_{1} \mathrm{M}_{0}$ \\
\hline UT-SCC-43B & 0.33 & 2.2 & Gingiva & $\mathrm{T}_{4} \mathrm{~N}_{1} \mathrm{M}_{0}$ \\
\hline UT-SCC-45 & 0.14 & 2.0 & Floor of mouth & $\mathrm{T}_{3} \mathrm{~N}_{1} \mathrm{M}_{0}$ \\
\hline UT-SCC-46A & 0.44 & 1.6 & Gingiva & $\mathrm{T}_{1} \mathrm{~N}_{0} \mathrm{M}_{0}$ \\
\hline UT-SCC-47 & 0.65 & 2.0 & Floor of mouth & $\mathrm{T}_{2} \mathrm{~N}_{0} \mathrm{M}_{0}$ \\
\hline UT-SCC-54A & 0.45 & 2.3 & Buccal mucosa & $\mathrm{T}_{2} \mathrm{~N}_{0} \mathrm{M}_{0}$ \\
\hline UT-SCC-60B & 0.65 & 2.2 & Tonsil & $\mathrm{T}_{4} \mathrm{~N}_{1} \mathrm{M}_{0}$ \\
\hline UT-SCC-76A & 0.84 & 2.5 & Tongue & $\mathrm{T}_{3} \mathrm{~N}_{0} \mathrm{M}_{0}$ \\
\hline UT-SCC-77 & 0.34 & 2.5 & Tongue & $\mathrm{T}_{1} \mathrm{~N}_{0} \mathrm{M}_{0}$ \\
\hline
\end{tabular}

${ }^{\mathrm{a}} \mathrm{ICS}$ given in terms of surviving fraction $(1 \mathrm{~h}$ exposure to cisplatin; $1 \mu \mathrm{g} / \mathrm{ml})$; ${ }^{\mathrm{b}} \mathrm{IR}$ given in terms of mean inactivation dose $($ AUC $=$ area under curve). Previously published by Pekkola-Heino et al (19) and Erjala et al (32); 'TNM classification according to the International Union against Cancer (IUCC, 1977).

possible combinations of one or more factors. The computer then selected the combination of factors with the strongest correlation to ICS.

\section{Results}

Radio- and cisplatin sensitivity. The intrinsic cisplatin sensitivity (ICS) of 39 cell lines from head and neck tumors was determined using a clonogenic assay. ICS is reported in terms of the surviving fraction of cells, and varied from 0.00 to 1.00 , with a median of 0.52 in the investigated cell lines (Table I). The intrinsic radiosensitivity (IR) of these cell lines was previously determined (19). The IR was given in terms of mean inactivation dose (AUC = area under curve), and varied between 1.4 and 2.6, with a median of 2.0 (Table I).

Four cell lines showed resistance to both cisplatin and radiation (UT-SCC-24A, -33, -34, and -76A), while three were sensitive to both treatments (UT-SCC-17, -23 , and -46A). 
A

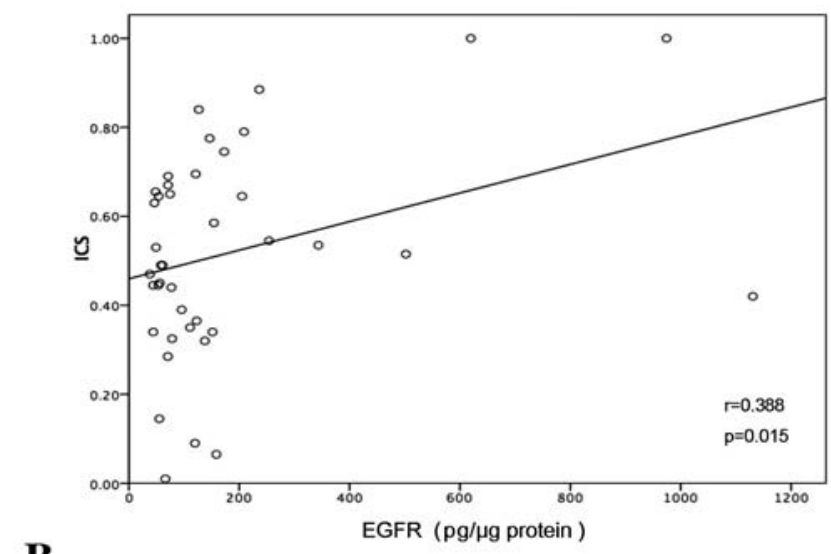

B

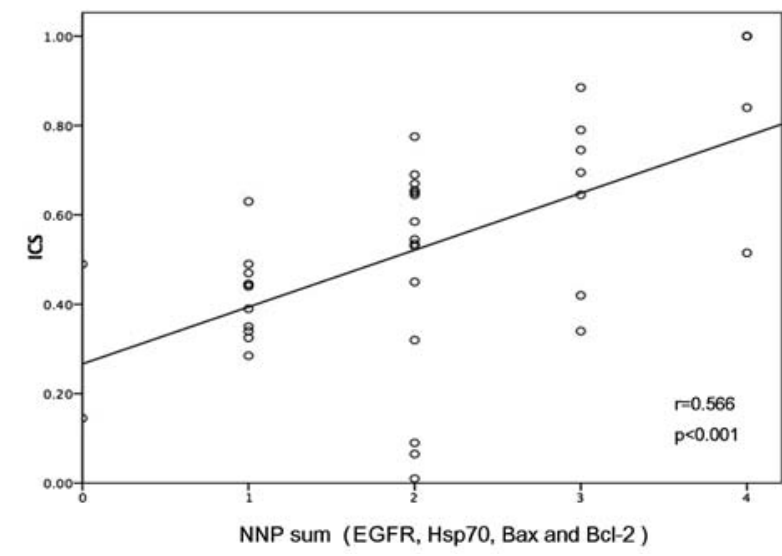

Figure 1. (A) Pearson's correlation analysis of the protein expression (determined by ELISA) of EGFR and the intrinsic cisplatin sensitivity (ICS) in 39 head and neck squamous cell carcinoma cell lines $(r=0.388, p=0.015)$. (B) Pearson's correlation analysis of the Number of Negative Points (NNP) sum for the proteins EGFR, Hsp70, Bax, and Bcl-2 ( $\mathrm{r}=0.566, \mathrm{p}<0.001)$.

However, there were also cell lines that were sensitive to one treatment but resistant to the other (UT-SCC-2, -9, -12A, and -77), and statistical analysis did not show any correlation between cisplatin and radiosensitivity (Pearson's correlation test, $\mathrm{r}=0.138, \mathrm{p}=0.401$; data not shown). Thus, it can be concluded that intrinsic radiosensitivity is not a predictive factor for cisplatin treatment outcome.

Proteins influencing ICS. The expression of EGFR, Hsp70, Bax, Bcl-2, Bcl-XL, survivin, and COX-2 in 39 HNSCC cell lines was determined and correlated to cisplatin sensitivity. EGFR was the only protein that alone showed a significant correlation to the ICS when using protein expression values obtained by ELISA (Pearson's correlation test, $\mathrm{r}=0.388$, $\mathrm{p}=0.015$; Fig. 1A). In order to evaluate if combinations of the selected proteins were of value for the prediction of cisplatin treatment response, each protein was given 0-3 points in the NNP system depending on its level of expression as compared to NOK (see Material and methods). For each cell line, the NNP sum for the different combinations of proteins was then calculated and correlated to the ICS. The combination of EGFR, Hsp70, Bax, and Bcl-2 was found to yield the strongest correlation $(\mathrm{r}=0.566, \mathrm{p}<0.001)$ with Bax showing the second largest influence on ICS (Fig. 1B).
$\mathbf{A}$
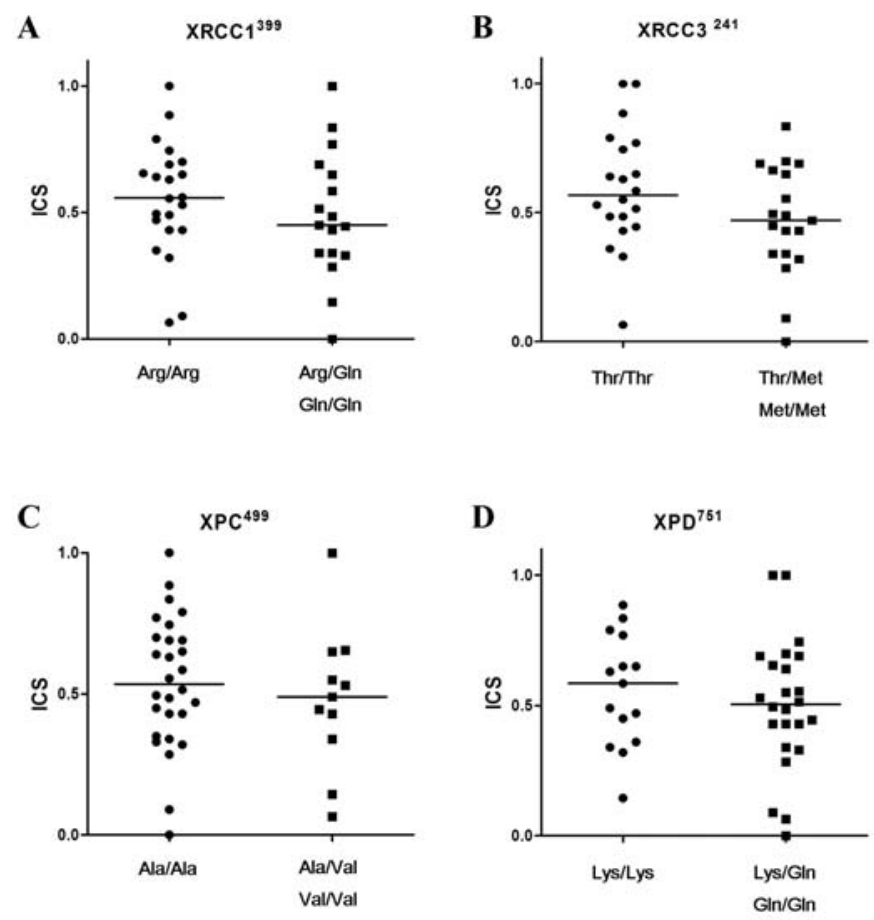

Figure 2. Intrinsic cisplatin sensitivity (ICS) in 39 head and neck squamous cell carcinoma cell lines in relation to the presence of single nucleotide polymorphisms within the four DNA repair genes, (A) XRCC1 $(\mathrm{p}=0.295)$, (B) XRCC3 $(p=0.122),(C) \operatorname{XPC}(p=0.473)$, and (D) XPD $(p=0.507)$. Horizontal lines represent median values. The Mann-Whitney $U$ test was used for evaluation of statistical significance.

Relationship between ICS and SNPs within genes involved in DNA repair, growth control, and apoptosis. Since cisplatin forms DNA adducts in exposed cells, we hypothesized that SNPs within DNA repair genes affect the cellular response to this drug. For that reason, the correlation between ICS and SNPs in four DNA repair genes, $\mathrm{XPC}^{499}, \mathrm{XPD}^{751}, \mathrm{XRCC}^{399}$, and XRCC $3^{241}$ was analyzed. As seen in Fig. 2, all four SNPs tended to increase the cisplatin sensitivity, as the median ICS for the group of cell lines carrying at least one variant allele was lower than the median ICS in the homozygous wild-type group in all four cases. Moreover, the SNP FGFR4 ${ }^{388}$ also appeared to be associated with an increase in cisplatin sensitivity (Fig. 3A). However, no statistically significant differences were obtained using the Mann-Whitney $U$ test for either of the above-mentioned SNPs.

Genes involved in cell proliferation and growth control have been suggested to influence the response to anti-cancer treatment. Therefore, the possible predictive role of the SNPs, $\mathrm{p} 53^{72}$ and MDM2 $2^{309}$ for cisplatin treatment of head and neck tumors was evaluated. However, neither of these two SNPs showed any tendency to affect ICS (Fig. 3B and C).

Combining factors on the protein and gene level for the prediction of ICS. The NNP system was used for the analyses of the combined effect of changes in protein expression and the presence of SNPs on cisplatin sensitivity. As mentioned earlier, each protein generated 0-3 points, positive or negative, in the NNP system, depending on the level of expression. p53 $3^{72}$ or MDM2 ${ }^{309}$ SNPs were both considered to reduce 
A
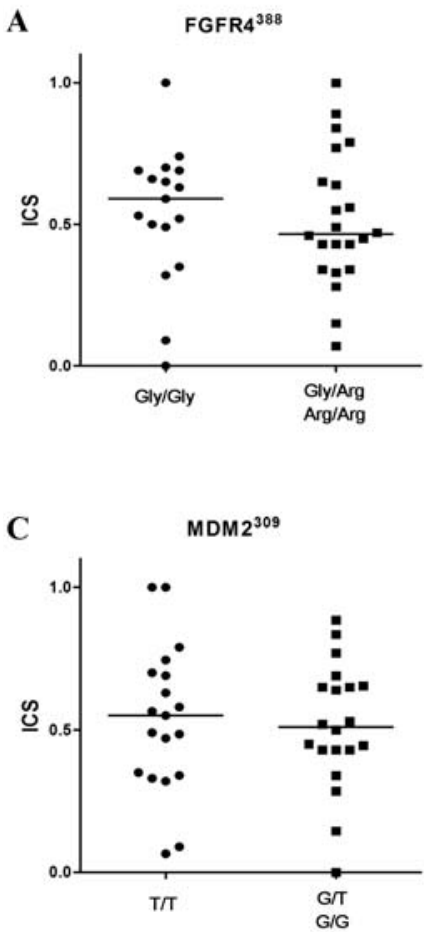

Figure 3. Intrinsic cisplatin sensitivity (ICS) in 39 head and neck squamous cell carcinoma cell lines in relation to the presence of single nucleotide polymorphisms within three genes involved in cell death and growth, (A) FGFR4 ( $\mathrm{p}=0.344),(B) \mathrm{p} 53(\mathrm{p}=0.585)$, and (C) MDM2 ( $\mathrm{p}=0.811)$. Horizontal lines represent median values. The Mann-Whitney U test was used for evaluation of statistical significance.

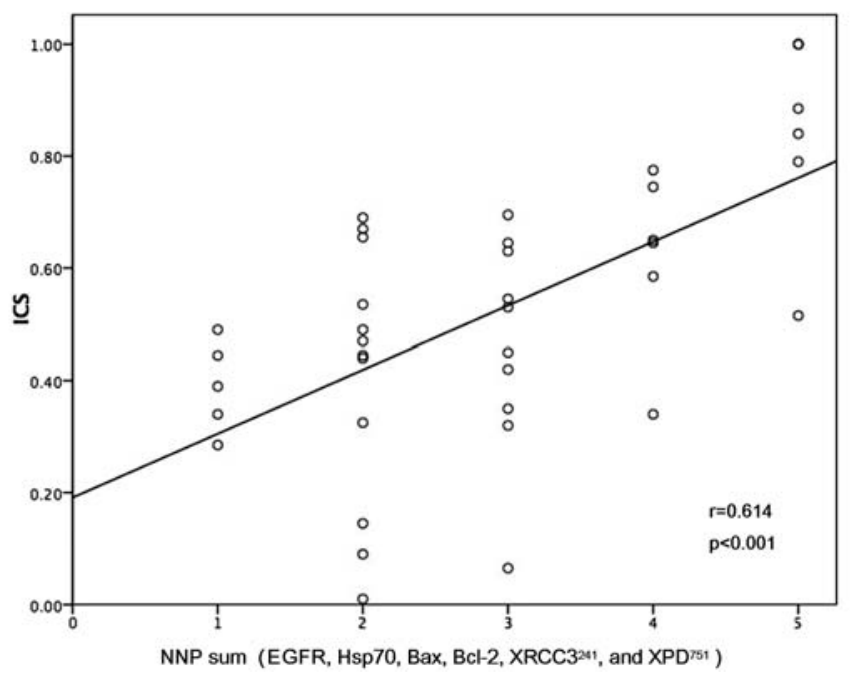

Figure 4. Pearson's correlation analysis of the intrinsic cisplatin sensitivity (ICS) and the Number of Negative Points (NNP) sum for EGFR, Hsp70, Bax, $\mathrm{Bcl}-2, \mathrm{XRCC}^{241}$, and $\mathrm{XPD}^{751}$, which gave the strongest correlation to ICS $(r=0.614, p<0.001)$, in 39 head and neck squamous cell carcinoma cell lines.

cisplatin sensitivity and cell lines harboring these SNPs received one positive point in the NNP system. The XRCC1 ${ }^{399}$, $\mathrm{XRCC}^{241}, \mathrm{XPD}^{751}, \mathrm{XPC}^{499}$, and FGFR4 ${ }^{388}$ SNPs, on the other hand, each generated one negative point, as they were all considered to increase the treatment sensitivity, and are, thus, advantageous from a patient perspective.
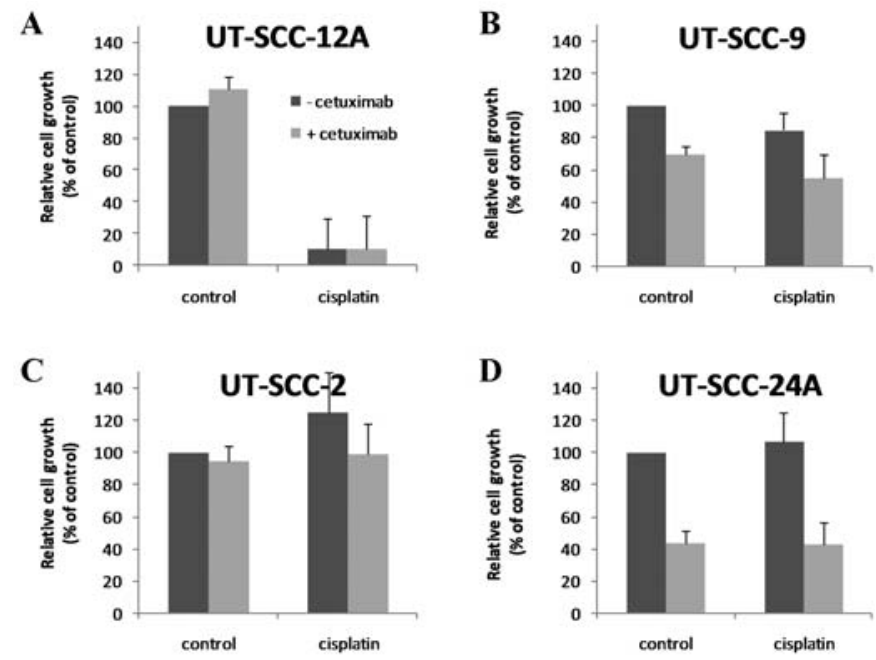

Figure 5. Cytostatic/cytotoxic effects of the anti-EGFR antibody cetuximab (Erbitux; $30 \mathrm{ng} / \mathrm{ml}, 48 \mathrm{~h}$ ) alone or in combination with cisplatin $(1 \mu \mathrm{g} / \mathrm{ml}, 1 \mathrm{~h})$ in four head and neck squamous cell carcinoma cell lines with different EGFR protein expression levels, (A) UT-SCC-12A (71 pg/ $\mu \mathrm{g}$ protein which is comparable to the expression level in NOK; $52 \mathrm{pg} / \mu \mathrm{g}$ protein), (B) UTSCC-9 (236 pg/ $\mu \mathrm{g}$ protein), (C) UT-SCC-2 (620 pg/ $\mu \mathrm{g}$ protein), and (D) UT-SCC-24A (974 pg/ $\mu$ g protein). Seven days after cisplatin exposure, cells were stained with crystal violet. The dye was solubilized by addition of $1 \%$ SDS, and samples were analyzed in a spectrophotometer at $550 \mathrm{~nm}$.

In order to extract the combination of factors with the highest correlation to ICS, we performed a multivariate statistical computer analysis. The result of this calculation showed that out of all possible combinations, EGFR, Hsp70, $\mathrm{Bax}, \mathrm{Bcl}-2, \mathrm{XRCC}^{241}$, and $\mathrm{XPD}^{751}$ gave the strongest correlation to ICS (Pearson's correlation test; $r=0.614, p<0.001$; Fig. 4).

Importance of EGFR for ICS. Since expression of EGFR was the only factor that alone was significantly correlated to ICS, the role of this tyrosine kinase receptor in cisplatin treatment response was further evaluated. Four of the 39 HNSCC cell lines, each with unique expression levels of EGFR, were treated with the monoclonal anti-EGFR antibody, cetuximab, alone or in combination with cisplatin. Cetuximab treatment alone resulted in a decrease in cell survival in UT-SCC-9 and -24A cultures, which exhibited a 4- and 19-fold overexpression of EGFR as compared to NOK, respectively (Fig. 5B and D). UT-SCC-12A cultures, with EGFR expression levels close to that of NOK, did not respond to cetuximab treatment, and neither did UT-SCC-2 despite a 12-fold overexpression of EGFR (Fig. 5A and C). Cisplatin alone triggered cell death only in UT-SCC-12A and -9 cells, the two cell lines with the lowest expression of EGFR (Fig. 5A and B). An additive effect of cisplatin and cetuximab treatment was observed only in UT-SCC-9 cultures (Fig. 5B).

\section{Discussion}

Concomitant chemoradiotherapy has emerged as an effective treatment for advanced HNSCC, but unfortunately this treatment also increases toxicity in normal tissue. This underscores the need for further improvement concerning the prediction of treatment sensitivity. Cisplatin is one of the most 
frequently used drugs during chemoradiotherapy for HNSCC. The choice of treatment is still based primarily on tumornode-metastasis (TNM) stages, but since resistance and local carcinoma recurrences are significant clinical problems, the introduction of biological markers for the prediction of treatment response would be beneficial.

The aim of the present study was to find a panel of factors that predicts the outcome of cisplatin therapy, since it appears that no single factor alone can predict ICS. Since changes in protein expression, as well as genetic alterations, could influence treatment outcome, a method in which both types of factors were evaluated simultaneously was required. By using our own recently published method called the NNP system (17), protein expression values from ELISA analyses were converted into points between 0 and 3 depending on the relative expression in each cell line, as compared to NOK. In the same way, each SNP generated one point in the NNP system. Finally, a NNP sum for different combinations of factors could be calculated and correlated to the ICS. A possible weakness of the method is that even though the studied factors may have varying impact on treatment sensitivity, for simplicity, all factors were presumed to be of equal importance in the NNP system. However, we believe that it is vital to construct a system that enables the evaluation of a combination of factors, as it is generally accepted that single factors will not predict treatment sensitivity.

When using either the NNP system or the protein values from the ELISA analyses, the expression of EGFR was found to be significantly correlated to ICS. Four cell lines representing different EGFR expression levels were further evaluated to investigate whether EGFR is a strong predictive marker for ICS. Cisplatin alone triggered cell death only in UT-SCC-12A and -9 , two cell lines with low expression of EGFR (Fig. 5A and B). Had EGFR been a strong independent predictive factor of cisplatin treatment response, inhibition of EGFR function would probably increase the cisplatin sensitivity in EGFR overexpressing cells. The anti-EGFR antibody, cetuximab, alone had a cytotoxic effect in UT-SCC-9 and -24A cultures, which exhibit a 4- and 19-fold overexpression of EGFR, respectively. In contrast, neither UT-SCC- 2 cultures with a 12-fold overexpression of EGFR, nor UT-SCC-12A cells expressing near to normal levels of EGFR responded to cetuximab treatment (Fig. 5C and A). The former could possibly be explained by the presence of additional molecular changes in this cell line, such as constitutive activation of downstream signaling molecules, which would render these tumor cells independent of EGFR signaling. When cells were exposed to cisplatin in combination with cetuximab, there was no synergistic effect observed. In UT-SCC-9 cultures merely an additive effect of cisplatin and cetuximab treatment was observed. However, it should be noted that even though inhibition of EGFR signaling did not increase the cisplatin sensitivity, treatment with a combination of cisplatin and cetuximab proved beneficial in these four cell lines, since an increased number responded to treatment. Similar results were obtained in a phase III clinical trial of 117 recurrent/ metastatic HNSCC patients where a significant improvement in response rate after treatment with cisplatin plus cetuximab versus cisplatin alone (26 and 10\%, respectively) was observed. However, there was no difference in progression free or overall survival (23). Our results from this part of the study suggest that EGFR is not a satisfying single predictive factor of cisplatin treatment response, but additional factors should be evaluated in order to achieve a more accurate prediction.

When combined with EGFR, both Hsp70 and Bax improved the correlation to ICS. However, neither Hsp70 nor Bax showed significant correlations to ICS on its own. In support of this finding, Hsp70 was previously linked to treatment response in breast cancer, where high expression was associated with resistance to combination chemotherapies (24). Furthermore, low expression of Bax was associated with poor survival of patients with locally advanced esophageal cancer after chemotherapy (5-fluorouracil and cisplatin) (25). Bax was also found to be an independent predictive factor of response to neoadjuvant (cisplatin-based) chemotherapy in the management of oral cancer (26).

Two SNPs in genes involved in the p53 stress response pathway were included, since p53 is one of the most welldocumented tumor suppressor genes. In the p53 gene itself, there is a SNP at codon 72 encoding either a proline or an arginine residue, and the arginine allele was correlated with poor apoptosis in HNSCC (27). A SNP in the MDM2 ${ }^{309}$ gene has been shown to increase the intracellular level of MDM2, and thereby blocks the $\mathrm{p} 53$ response which results in enhanced cancer formation (28). We could not detect a tendency of these two SNPs to impact cisplatin sensitivity in our 39 cell lines. These results were in line with results published by Hoffmann et al showing that the presence of single alterations in the p53 pathway is not a reliable predictor for the response to cisplatin or radiotherapy in HNSCC (29).

SNPs in several DNA repair genes have been identified, but their biological significance is not yet fully understood. It has been reported that the presence of polymorphic variants of DNA repair genes (XPD, ERCC1, and XRCC1) is a prognostic factor for cisplatin treatment among HNSCC patients (30). Similarly, SNPs within the XPD and XRCC3 genes were found to be linked to cisplatin response in esophagogastric cancer (31). In the present study, all investigated SNPs in DNA repair genes tended to increase cisplatin sensitivity, and when combining all proteins and SNPs, the XRCC $3^{241}$ and $\mathrm{XPD}^{751}$ SNP increased the correlation between the NNP sum and ICS. On the other hand, when we analyzed the impact of these SNPs on radiosensitivity, we found no tendencies to affect the IR of the investigated 39 cell lines (data not shown). Furthermore, since no correlation was found between IR and ICS, it appears that different panels of factors are required for prediction of radio- and chemotherapy response.

Taken together, we identified proteins and SNPs in this study that could be included in a panel of biomarkers for the prediction of cisplatin treatment response. These results could, after verification in a large number of tumors, lead to a more effective and individualized therapy for HNSCC patients.

\section{Acknowledgements}

We thank Annika Magnussen, Annette Molbaek, and Åsa Schippert for technical assistance. This study was supported by the Swedish Laryng Foundation, the County Council of Östergötland (ÖLL), the Research Council of South Eastern Sweden (FORSS), The Swedish Cancer 
Foundation (no 070180), The Cancer and Allergy Foundation of Sweden, The Cancer Foundation of Östergötland, and the Research Funds of Linköping University Hospital.

\section{References}

1. Shah JP and Lydiatt W: Treatment of cancer of the head and neck. CA Cancer J Clin 45: 352-368, 1995.

2. Friedman NR: Prognostic factors for local recurrence, metastases, and survival rates in squamous cell carcinoma of the skin, ear, and lip. J Am Acad Dermatol 28: 281-282, 1993.

3. Bakkenist CJ and Kastan MB: DNA damage activates ATM through intermolecular autophosphorylation and dimer dissociation. Nature 421: 499-506, 2003.

4. Bauer JA, Kumar B, Cordell KG, et al: Targeting apoptosis to overcome cisplatin resistance: a translational study in head and neck cancer. Int J Radiat Oncol Biol Phys 69: S106-S108, 2007.

5. Guo B, Cao S, Toth K, Azrak RG and Rustum YM: Overexpression of Bax enhances antitumor activity of chemotherapeutic agents in human head and neck squamous cell carcinoma. Clin Cancer Res 6: 718-724, 2000.

6. Yu J, Yue W, Wu B and Zhang L: PUMA sensitizes lung cancer cells to chemotherapeutic agents and irradiation. Clin Cancer Res 12: 2928-2936, 2006

7. Ang KK, Berkey BA, Tu X, et al: Impact of epidermal growth factor receptor expression on survival and pattern of relapse in patients with advanced head and neck carcinoma. Cancer Res 62: 7350-7356, 2002.

8. Loeffler-Ragg J, Schwentner I, Sprinzl GM and Zwierzina H: EGFR inhibition as a therapy for head and neck squamous cell carcinoma. Expert Opin Investig Drugs 17: 1517-1531, 2008.

9. Dubois RN, Abramson SB, Crofford L, et al: Cyclooxygenase in biology and disease. FASEB J 12: 1063-1073, 1998.

10. Milas L: Cyclooxygenase-2 (COX-2) enzyme inhibitors as potential enhancers of tumor radioresponse. Semin Radiat Oncol 11: 290-299, 2001.

11. Koki AT, Leahy KM and Masferrer JL: Potential utility of COX-2 inhibitors in chemoprevention and chemotherapy. Expert Opin Investig Drugs 8: 1623-1638, 1999.

12. Lo Muzio L, Pannone G, Staibano S, et al: Survivin expression in oral squamous cell carcinoma. Br J Cancer 89: 2244-2248, 2003.

13. Garrido C, Brunet M, Didelot C, Zermati Y, Schmitt E and Kroemer G: Heat shock proteins 27 and 70: anti-apoptotic proteins with tumorigenic properties. Cell Cycle 5: 2592-2601, 2006.

14. Zhan Q, Bae I, Kastan MB and Fornace AJ Jr: The p53dependent gamma-ray response of GADD45. Cancer Res 54: 2755-2760, 1994.

15. Powers CJ, McLeskey SW and Wellstein A: Fibroblast growth factors, their receptors and signaling. Endocr Relat Cancer 7: 165-197, 2000

16. Ansell A, Farnebo L, Grenman R, Roberg K and Thunell LK: Polymorphism of FGFR4 in cancer development and sensitivity to cisplatin and radiation in head and neck cancer. Oral Oncol 45: 23-29, 2009.

17. Farnebo L, Jerhammar F, Vainikka L, Grenman R, NorbergSpaak L and Roberg K: Number of negative points: a novel method for predicting radiosensitivity in head and neck tumor cell lines. Oncol Rep 20: 453-461, 2008.
18. Nilsson JA, Hedberg JJ, Vondracek M, et al: Alcohol dehydrogenase 3 transcription associates with proliferation of human oral keratinocytes. Cell Mol Life Sci 61: 610-617, 2004.

19. Pekkola-Heino K, Jaakkola M, Kulmala J and Grenman R: Comparison of cellular radiosensitivity between different localizations of head and neck squamous-cell carcinoma. J Cancer Res Clin Oncol 121: 452-456, 1995.

20. Grenman R, Burk D, Virolainen E, et al: Clonogenic cell assay for anchorage-dependent squamous carcinoma cell lines using limiting dilution. Int J Cancer 44: 131-136, 1989.

21. Fertil B, Deschavanne PJ, Gueulette J, Possoz A, Wambersie A and Malaise EP: In vitro radiosensitivity of six human cell lines. II. Relation to the RBE of $50-\mathrm{MeV}$ neutrons. Radiat Res 90: 526$537,1982$.

22. Lowry OH, Rosebrough NJ, Farr AL and Randall RJ: Protein measurement with the Folin phenol reagent. J Biol Chem 193: 265-275, 1951

23. Burtness B: Cetuximab and cisplatin for chemotherapyrefractory squamous cell cancer of the head and neck. J Clin Oncol 23: 5440-5442, 2005.

24. Vargas-Roig LM, Gago FE, Tello O, Aznar JC and Ciocca DR: Heat shock protein expression and drug resistance in breast cancer patients treated with induction chemotherapy. Int J Cancer 79: 468-475, 1998.

25. Kang SY, Han JH, Lee KJ, et al: Low expression of Bax predicts poor prognosis in patients with locally advanced esophageal cancer treated with definitive chemoradiotherapy. Clin Cancer Res 13: 4146-4153, 2007.

26. Tsuji T, Noguchi M, Kido Y, et al: Predictive assay of neoadjuvant chemotherapy in management of oral cancer. Int J Oral Maxillofac Surg 36: 15-19, 2007.

27. Schneider-Stock R, Mawrin C, Motsch C, et al: Retention of the arginine allele in codon 72 of the p53 gene correlates with poor apoptosis in head and neck cancer. Am J Pathol 164: 1233-1241, 2004.

28. Bond GL, Hu W and Levine A: A single nucleotide polymorphism in the MDM2 gene: from a molecular and cellular explanation to clinical effect. Cancer Res 65: 5481-5484, 2005.

29. Hoffmann TK, Sonkoly E, Hauser U, et al: Alterations in the p53 pathway and their association with radio- and chemosensitivity in head and neck squamous cell carcinoma. Oral Oncol 44: 1100-1109, 2008.

30. Quintela-Fandino M, Hitt R, Medina PP, et al: DNA-repair gene polymorphisms predict favorable clinical outcome among patients with advanced squamous cell carcinoma of the head and neck treated with cisplatin-based induction chemotherapy. J Clin Oncol 24: 4333-4339, 2006.

31. Font A, Salazar R, Maurel J, et al: Cisplatin plus weekly CPT11/docetaxel in advanced esophagogastric cancer: a phase I study with pharmacogenetic assessment of XPD, XRCC 3 and UGT1A1 polymorphisms. Cancer Chemother Pharmacol 62: 1075-1083, 2008.

32. Erjala K, Pulkkinen J, Kulmala J, Alanen K and Grenman R: Head and neck squamous cell carcinoma is highly sensitive to vinorelbine in vitro. Anticancer Res 22: 3135-3142, 2002. 